\title{
Б. Бикс
}

\section{ПРИМЕНЕНИЕ (И НЕПРАВИЛЬНОЕ ПРИМЕНЕНИЕ) ИДЕИ ВИТГЕНШТЕЙНА О СЛЕДОВАНИИ ПРАВИЛУ В ТЕОРИИ ПРАВА ${ }^{1}$}

\begin{abstract}
Исследуются идеи Витгенштейна о следовании правилам, современнье комментарии и попытки отдельных правоведов применить проблему следования правилу к вопросам толкования права. Показано, что и сторонники, и противники радикальной неопределенности права пытались использовать обсуждение Витгенштейном следования правилу для обоснования своих позиций, но обе стороны часто находили в Витгенитейне больше, чем есть на самом деле.

Ключевые слова: следование правилу, теория права, юридический язык, Витгенштейн.
\end{abstract}

Работы Витгенштейна о «следовании правилу» остаются важной - и горячо обсуждаемой - частью его поздней философии. «Правило» в его работах имело более важное и принципиальное значение по сравнению с тем, как этот термин используется во многих дискуссиях о практическом мышлении или теории права. То, как Витгенштейн употреблял «правило», относится ко всем нормативным ограничениям, применяемым в разнообразных ситуациях, и к практикам, когда наши действия, так сказать, управляются, и к ситуациям, в которых важно описание действий как «правильных» или «неправильных». Однако «он не стремился написать книгу о правилах, а хотел изучить особые проблемы понимания, возникающие из нормативной природы языка, логики и рассуждений» [1. Р. 39]. В частности, он рассматривал нормативные действия, которые с виду не вызывают беспокойства или не кажутся трудными для понимания: например, правильное употребление слова, понимание знака-указателя и продолжение простой математической последовательности [2. § 143-242]. Интересным в таких примерах представляется не вопрос, является ли правильным или неправильным определенный ответ или продолжение; Витгенштейн определенно подбирал примеры, где по этому поводу было бы согласие. Но вопрос, правила или мы сами делаем наши ответы правильными или неправильными (или что влияет на эту оценку)?

Обсуждение Витгенштейном следования правилу оказало влияние на проблему правовой определенности, прежде всего, на тех, кто утверждал, что право является радикально неопределенным. Чтобы обосновать точку зрения, что у правил нет определенного применения, они предложили читать Вит-

${ }^{1}$ Перевод с английского выполнен В.В. Оглезневым под редакцией В.А. Суровцева по изданию Bix B. The Application (and Mis-Application) of Wittgenstein's Rule-Following Considerations to Legal Theory // Canadian Journal of Law and Jurisprudence. 1990. Vol. III, No. 2. P. 107-121. Публикуется с разрешения автора.

Перевод статьи подготовлен в рамках поддержанного Советом по грантам Президента РФ научного проекта № МД-137.2020.6. 
генштейна так, как это делал Крипке [3; 4. Р. 613] ${ }^{1}$. Их аргументация строится по следующему принципу. Витгенштейн (Крипке) показал: нет смысла доказывать, что под нынешним употреблением слова я имею в виду то же самое, что и при предшествующем употреблении, и нет смысла доказывать, что я применяю слово (т.е. правило его употребления) правильно [3. Р. 70 71]. Более того, «нет ничего, что подтверждает наше прошлое употребление, намерение или отношение к слову... которое контролирует или ограничивает наше будущее его употребление» [4. Р. 628]. Но если нет ничего, что говорит нам, как употреблять слово, и если любой способ продолжения последовательности можно назвать следованием правилу, то тогда, кажется, можно все, что угодно [3. Р. 11-13, 77-78, 84-93; 4. Р. 632] ${ }^{2}$. Вот поэтому сторонники правовой неопределенности соглашаются с Витгенштейном (Крипке), что суждения о правильности и неправильности (в следовании правилу или в употреблении слова), т.е. вся теория значения, основаны (могут быть основаны только) на согласии сообщества. Мы употребляем слово правильно, если и только если наше употребление согласуется с тем, как это делает большинство наших сограждан [3. Р. 90-98, 110-112; 4. 632-636]. Этот подход хорошо согласуется с позицией многих сторонников правовой неопределенности. Им не надо отрицать (и они не отрицают), что в праве есть «простые случаи». Но простоту этих случаев они приписывают не языку, а (временному) согласию общества (или соответствующего юридического сообщества) [4. Р. 632636; 5. Р. 917, 918-920, 929-945; 6. Р. 54-56, 60-69]. У такого согласия есть политический или идеологический компонент, который, как некоторые могли бы сказать, навязан более могущественными членами сообщества. Если и когда идеология общества изменится, то, согласно этому подходу, случаи, которые считались простыми, тоже изменятся [4. Р. 632-636].

\section{II}

Выводы Витгенштейна были другими ${ }^{3}$. Крипке правильно утверждал, что, по мнению Витгенштейна, нет ни одного факта (ни одного «сверх-

${ }^{1}$ В одном месте своей книги Крипке предлагает прочтение, в котором разрабатываемый им аргумент на самом деле относится к тому, как Витгенштейна понимает сам Крипке. В другом месте то, что он приписывает Витгенштейну, более соответствует. Моя точка зрения заключается в том, что прочтение Крипке неадекватно отражает позицию Витгенштейна и что действительная позиция Витгенштейна выходит за рамки той, которую Крипке (в той или иной степени) ему приписывает. Пока я буду предлагать аргументы, чтобы поддержать оба эти утверждения, моей целью не является их более глубокое рассмотрение.

2 «Наш парадокс был таким: ни один образ действий не мог бы определяться каким-то правилом, поскольку любой образ действий можно привести в соответствие с этим правилом. Ответом служило: если все можно привести в соответствие с данным правилом, то все может быть приведено и в противоречие с этим правилом. Поэтому тут не было бы ни соответствия, ни противоречия... Мы здесь сталкиваемся с определенным непониманием...» [2. § 201].

${ }^{3}$ Очень сложно (если вообще возможно) найти серьезного исследователя Витгенштейна, который определенно согласился бы с прочтением Крипке [7-14]. Замечу, что идеи Витгенштейна в «Философских исследованиях», относящиеся к следованию правилу, представлены в коротких пассажах, которые зачастую афористичны и загадочны. Прочтение отдельных аргументов или взглядов в этих комментариях требует явного или неявного прочувствования деталей и прояснения двусмысленностей. Поэтому предлагаемая мной интерпретация лишь приблизительна. Но так или иначе она в общем совпадает с интерпретациями, в числе других предложенными Питером Хакером, Городом Бейкером, Дэвидом Пэрсом, Джоном Макдауэлом, Колином Макгином и Саймоном Блэкберном (которые, несмотря на их несогласие относительно других аспектов философии Витгенштейна, согласны или более-менее согласны относительно аспектов следования правилу, относящихся к моему исследованию). 
факта» [2. § 192]), который обосновывает наше понимание правила ${ }^{1}$. Но он ошибался, изображая это как «скептическую проблему», для которой требуется «скептическое решение» [3. Р. 61-69] $]^{2}$. Если знаков и символов правила вдруг оказалось бы недостаточно для понимания того, соответствовало ли определенное действие правилу, то как тогда добавление в нашем сознании (или в платоновском мире идей) дополнительных знаков и символов могло бы этот недостаток исправить? Если мы «называем „интерпретацией“ лишь замену одного выражения правила другим», то «это свидетельствует о том, что существует такое понимание правила, которое является не интерпретациией (здесь и далее в цитатах курсив мой. - Б.Б.), а обнаруживается в том, что мы называем „следованием правилу“ и „действием вопреки“ правилу в реальных случаях его применения» [2. § 201]. Именно философское стремление и философское нетерпение обнаружить некоего магического посредника между правилами и действиями приводит к идее «скептической проблемы». Как писал Дэвид Пэрс, дело не только в том, что часто существует необходимость интерпретировать правила посредством определения их терминов, но и в том, что процесс определения термина, а затем определение терминов в определении не может заполнить все пробелы, потому что рано или поздно придется совершить скачок от языка к миру, не гарантированный никаким определением [13. Р. 432].

Есть ощущение, что даже обсуждение Пэрса слишком уступает критикам Витгенштейна: говорить о «пробелах» и о «скачке от языка к миру» - значит утверждать, что язык можно понять помимо его применения к миру и в мире. Витгенштейн такую позицию не одобрил бы.

По крайней мере, в простых случаях мы все применяем правила одинаковым образом. Например, мы все можем продолжить последовательность «прибавить 2»: «1000, 1002, 1004...» [2. § 185-187]. Слово «мы» в этих предложениях включает всех, кто разделяет одну и ту же форму жизни и кто одинаково обучался одним и тем же правилам. (Позднее я рассмотрю понятие формы жизни Витгенштейна.) Согласно этим простым случаям скептицизм не усиливается, если больше ничего нельзя предложить для оправдания применения правила. Жалоба скептика необоснованна, поскольку больше нет ничего такого, что могло бы быть предложено в качестве оправдания и что нужно в качестве оправдания ${ }^{3}$. Против скептика, который продолжает задавать вопросы, со временем могут понадобиться другие ответные меры. «Исчерпав свои основания, я достигну скального грунта, и моя лопата согнется.

${ }^{1}$ Саймон Блэкберн подметил, что Витгенштейн не стал бы выражаться в таких терминах [8. Р. 285]. И в качестве наиболее подходящей подходу Витгенштейна альтернативы предложил, что «рассмотрение термина определенным образом несколько отличается от представления чего-либо в качестве средства его понимания, или от принятия чего-либо в качестве средства его понимания» [8. P. 288].

${ }^{2}$ Криспин Райт указал, что прочтение Крипке ставит вверх дном предмет обсуждений Витгенштейна. Скептик Крипке заставляет нас задуматься, откуда мы можем знать, какому правилу мы следуем или следовали, и вообще задуматься о «самом существовании правил и следования им» [15. Р. 303]. Напротив, Витгенштейна особо интересовала «природа и эпистемология следования правилу», т.е. откуда мы можем знать, чего от нас требует правило в конкретной ситуации [15. Р. 303].

3 «Скептицизм не неопровержим, но явно бессмыслен, поскольку он пытается сомневаться там, где невозможно спрашивать. Ибо сомнение может существовать только там, где существует вопрос; вопрос - только там, где существует ответ, а ответ - лишь там, где нечто может быть высказано» [16. $\S 6.51]$. 
В таком случае я склонен сказать: „Вот так я действую“» [2. § 217]. Можно даже ответить так: «Это как раз то, что мы называем „прибавить 2“ (или „красным“ и т.д.)» [9. Р. 78, 85]. Но в языковой игре нет места для дополнительного оправдания или сомнения. «Если после полного обучения и всех рекомендованных проверок я все еще „сомневаюсь“, правильно ли я употребляю слово, мое „сомнение“ выходит за рамки языковой игры и автоматически превращается в концептуальный вопрос „Что считается следованием правилу?“» [13. Р. 442].

«Правильный ответ» на это вопрос аналогичен способу, которым мы склонны продолжать последовательность, но тот факт, что все мы продолжаем ее одинаковым образом, не делает этот ответ правильным (хотя, как я покажу далее, это именно то, что делает наши действия разумными). Чтобы установить, является ли цветок красным, мы не начинаем расспрашивать всех вокруг, что они думают о его цвете [17. § 431].

Как и Г.Л.А. Харт, Витгенштейн тяготел к умеренной позиции в отношении правила. Витгенштейн «пытался описать нормативность иначе, чем платоновской образ „правила как колея“, и объяснить, как возможен устойчивый компромисс между гипостазированием правил и отрицанием их существования» [15. Р. 297]. С одной стороны, Витгенштейн не хотел приписывать применение правила самим правилам как метафизическим сущностям. С другой стороны, он не желал отрицать, что (имеет смысл сказать, что) правило задает его правильное применение или интерпретацию [1. Р. 81-106].

\section{III}

Витгенштейн, обсуждая в «Философских исследованиях» следование правилу, уделял основное внимание простым случаям вроде математической последовательности «прибавить 2» [2. § 185-187]. В § 240 он пишет:

«Не прекращаются споры (скажем, среди математиков) о том, соблюдено правило или же нет. При этом, положим, до драки дело не доходит. Это присуще тому каркасу, на котором базируется работа языка (например, при описании)».

Витгенштейн рассматривал «простые случаи», потому что его интересовало, как устранить недоразумения и мифы, связанные с тем, что делает случаи применения слова или продолжения последовательности простыми. Ни ментальное состояние, ни внутренний голос или настроение, ни платоновская правило-сущность, которую мы каким-то образом схватываем, не могут считаться фактом, определяющим, как продолжать последовательность. Нет никой посреднической сущности, по мнению Витгенштейна, которая может оправдать или объяснить, почему мы делаем одно и то же, когда продолжаем последовательность «прибавить 2» или когда применяем слово «красный». Это как раз тот случай, когда люди, которые разделяют общую форму жизни и имеют одинаковую подготовку, продолжают одинаково следовать правилам. Как описал позицию Витгенштейна Джон Макдауэл, «наши действия содержаться только в тех реакция и ответах, которые мы усваиваем при обучении им» [18. Р. 149]. Ситуация несколько усложняется тем, что для Витгенштейна такие понятия, как «то же самое» и «согласие», не могут пониматься a priori или же независимо от проблемы следования правилу: 
Слово «согласие» и слово «правило» родственны друг другу, они двоюродные братья. Обучая кого-либо употреблять одно из этих слов, я тем самым учу и употреблению другого.

Употребление слова «правило» переплетено с употреблением слов «то же самое». (Как употребление слова «предложение»- с употреблением слова «истинный») [2. § 224-225].

По мнению Витгенштейна, простота ясных случаев возникает из неких основополагающих фактов согласованности суждений, согласованности социального контекста и стабильности мира. В $\S 242$ «Философских исследований» он заявляет:

«Языковое взаимопонимание достигается не только согласованностью определений, но (как ни странно это звучит) и согласованностью суждений. ...Одно дело, описывать методы измерения, другое - добывать и формулировать результаты измерений. А то, что мы называем «измерением», определяется и известным постоянством результатов измерения».

Короче говоря, «суждения» здесь содержат все связи, которые мы устанавливаем (посредством наших действий) между языком и миром: между правилом и его применением, между тем, как мы употребляли термин до этого, и тем, как мы его применяем к новому случаю, между тем, как мы обучились понимать действие (например, прибавление или измерение), и тем, как мы сами его совершаем и т.д. [10. Р. 57].

Дело в том, что после овладения математикой мы все одинаковым образом можем продолжить математическую последовательность «прибавить 2»; и до 1000 мы не разойдемся в своих ответах. После изучения, как пользоваться линейкой, наши измерения одного и того же объекта будут одинаковыми. Аналогичным образом, обучившись при помощи остенсивных определений употреблять слова, обозначающие цвет, мы все согласимся, что этот помидор красный, а эта трава целеная [19. Р. 342]. Если бы различия в индивидуальных суждениях приводили к расхождению в том, как люди продолжали последовательность «прибавить 2», или если бы нестабильный мир приводил к тому, что мы получали бы разные результаты всякий раз, когда измеряем один и тот же объект, тогда понятия этих действий - и сами действия - утратили бы смысл ${ }^{1}$.

Можно было бы сказать, что то, что после минимального обучения все мы на практике и при употреблении слов совершаем одни и те же действия, является просто счастливым совпадением ${ }^{2}$, хотя и совпадением, без которого коммуникация была бы невозможна [2. § 242]. В § 241 Витгенштейн пишет:

Итак, ты говоришь, что согласием людей решается, что верно, а что неверно? - Правильным или неправильным является то, что люди говорят;

${ }^{1}$ «Процедура взвешивания куска сыра: укладка его на весы, отклонение стрелки, указывающее его вес и, следовательно, цену, - потеряла бы всякий смысл, если бы мы часто сталкивались с тем, что сыр внезапно и без всякой причины разбухал бы или же усыхал» [2. § 142].

«“Если бы люди в общем и целом не были бы согласны относительно цвета вещей, если бы предопределенные случаи не были бы ожидаемы, тогда не существовало бы нашего понятия цвета." Нет - нашего понятия не существовало бы» [17. § 351].

2 «Мы могли бы сказать, что это удача, а не то, что (и это было бы предпочтительней) удача заключается в том, что жизнь на земле соответствует ее естественной атмосфере. Мы должны сказать, что соответствия столько, сколько нужно» [20. Р. 179]. 
и согласие людей относится к языку. Это - согласие не мнений, а формь жизни.

Следующая цитата приводится из неопубликованной рукописи Витгенштейна:

«Как устанавливается применение правила? Ты имеешь в виду „логическое“ установление? Либо при помощи других правил, либо никак! - Или ть имеешь в виду: как получается так, что мы согласны с одним его применением, но не с другим? Через обучение, тренировку и форму нашей жизни.

Это не вопрос согласия, но формы жизни» [1. Р. 258].

«Форма (формы) жизни» отчасти суммирует и отчасти намекает на объяснение факта нашего общего согласия [21. Р. 129-136]. Рудольф Хэллер показал, что Витгенштейн использовал эту фразу как минимум двумя разными способами: 1) (в единственном числе, Lebensform), чтобы кратко сформулировать «общечеловеческий образ действий», то, что явно и отчетливо человеческое; 2) (во множественном числе, Lebensformen), чтобы подчеркнуть различие между обществами и даже различие между сообществами одного общества [21. Р. 130-136; 22. Р. 58]. Роль, которую понятие «форма жизни» может сыграть в объяснении разногласий, будет обсуждаться в заключительной части этой статьи. Пока же рассмотрим анализ Витгенштейна согласия: мы продолжаем последовательность одинаковым образом из-за схожести нашего обучения и нашей природы. Но совсем не обязательно, чтобы все люди всегда одинаково реагировали бы на всевозможные обстоятельства; там, где нет одинакового продолжения последовательности, просто не будет устойчивых действий.

Противопоставляя Л. Витгенштейна отдельным сторонникам критических правовых исследований, я не имею в виду, что с помощью его идей можно было бы оспорить позицию критических правоведов, что некоторые «ясные случаи» являются таковыми в силу политического или идеологического согласия, а не в силу какого-либо строгого требования правильного или неправильного употребления слов. То, что некоторые действия являются или не являются нарушением «права равной защиты», может показаться ясным и очевидным; но ясность вопроса может исчезнуть, если мы продвинемся во времени на поколение вперед или назад. Наконец, я не уверен, что есть четкая грань между «ясными случаями», которые подпадают под обсуждение Витгенштейна «следования правилу», и теми, что не подпадают. То есть я не уверен, что можно быть вообще (что вряд ли) уверенным в том, какие вопросы интерпретации полностью выходят за рамки текущего обсуждения («за рамки языковой игры»).

\section{IV}

Если есть опасность (представленная Крипке и другими) прочтения Витгенштейна относительно следованию правилу как скептического, в отношении установления значения и достоверности, то также есть и противоположная опасность слишком вольного прочтения того, в чем уверяет Витгенштейн. Он хотел нас заверить, что, несмотря на отсутствие (по причине отсутствия) неких «внутренних» или платоновских фактов, мы можем говорить о «правильном» и «неправильном» даже самом элементарном нормативном поведении, включая применение слов и ответы на самые простые 
математические вопросы. Опасность слишком вольного прочтения возникает тогда, когда послание Витгенштейна читается как гарантированное приписывание правильности или достижимости согласия в отношении более спорных вопросов. Например, Брайан Лангил правильно утверждал, что правоведы могли бы не использовать идеи Л. Витгенштейна для обоснования радикальной неопределенности права, но он зашел слишком далеко, подразумевая, что правильное понимание Витгенштейна можно было бы использовать для опровержения всего скептического анализа права [23. Р. 451; 24. Р. 145].

Особое внимание Лангил уделял «убедительным утверждениям относительно неопределенности языка и влиянию этой предполагаемой неопределенности на наши представления о природе конституционного дискурса» [23. Р. 452]. Но отдельной его целью были те правоведы, которые утверждали, что работы Витгенштейна были основой их аргументации. По вышеизложенным причинам я согласен с Лангилом, что Л. Витгенштейн не верил, что язык радикально неопределенен и вряд ли с помощью его работ можно поддержать выводы сторонников правовой неопределенности [23. Р. 452-475, 486-495]. Но я не согласен с попыткой Лангила представить его прочтение Витгенштейна как шаг вперед в «объяснении грамматики права и... грамматики конституционной юриспруденции» [23. Р. 498; 25. Р. 549, 558-562] ${ }^{1}$.

Л. Витгенштейн использовал «грамматику» несколько шире, чем его обычное, но определенно с ним связанное употребление [1. Р. 34-64]. «[По мнению Витгенштейна] грамматика термина включает в себя разнообразные действия, связанные с его употреблением, а также критерии и фоновые условия, которые определяют его обычное применение» [26. Р. Х]. Грамматика фразы отчасти задается правилами, которые детерминируют использование этой фразы, так что если эти правила будут нарушены, итоговое предложение не будет иметь смысла. Это относится, например, к грамматике чисел, которым нельзя приписать цвет, и к грамматике боли, когда нельзя заявлять о сомнениях в своей боли [2. § 246].

Витгенштейн утверждал, что многие философские проблемы возникали в результате нарушения грамматических правил (например, ошибочного применения грамматики высказываний о материальных объектных к психологическим высказываниям от первого лица) [17. § 434]. Если бы мы строго следовали исключительно грамматике термина и оставались бы в рамках рассматриваемой языковой игры, то мы, как он считал, смогли бы избежать метафизической путаницы и соблазнов скептицизма [2. § 90, 520].

Когда Лангил, чтобы обосновать свои утверждения, что «грамматика права» и закона «основана на фундаменте практики» [23. Р. 497-498], использовал аргументы Л. Витгенштейна о важности человеческой природы и действий для значения простых терминов, он не следовал идеям философа, но пренебрег ими. Он сделал лишь то, от чего Витгенштейн предостерегал, а именно не рассматривать термины (в данном случае такие понятия Витгенштейна, как «грамматика», «практика» и «фундамент») вне обычного контекста их употребления, вне языковой игры. Витгенштейн же использовал эти понятия для анализа «ясных случаев» и необдуманного применения.

\footnotetext{
${ }^{1}$ Все просто: Витгенштейн употреблял термин «грамматика» в разговоре о словах и понятиях... и перенесение этотого аналитического инструмента в другие области, например в область социальной практики, в лучшем случае вводит в заблуждение.
} 
Прыжок от грамматики языка к «грамматике права» подразумевает, что определения юридических терминов и действий внутри юридического дискурса не могут разумно оспариваться и не нуждаются в дальнейшем оправдании. Я не заявляю, что подход Витгенштейна или даже его анализ «грамматики» не могут принести никакой пользы для анализа социальных институтов или социальной теории [26]. Однако Лангил, совершая важный переход к «грамматике права», не обосновывает ни сам этот переход, ни даже его необходимость.

Краткие и невнятные комментарии Лангила намекают на аргумент, который поддержать невозможно. Наряду со ссылкой на «грамматику права» и «грамматику конституционной юриспруденции» Лангил описал Оуэна Фисса как человека, разработавшего «,структурные условия“ для витгенштейновского взгляда на право - существование набора ограничительных правил, используемых судьями как социальной группой» [23. Р. 498], и заявил, что «идея Харта о судьях, применяющих социальные правила с внутренней точки зрения, позволила ключевой мысли Витгенштейна о следовании правилу занять место в судебном процессе» [23. Р. 499]. Согласно этому контексту комментарии Лангила, по-видимому, подразумевают, что для него юридическая практика подобна продолжению последовательности «прибавить 2» или применению термина «красный», которые не нуждаются в дальнейшем обосновании (и что любое существующее в области права согласие можно было бы объяснить во многом так же, как Витгенштейн объяснял одинаковое продолжение последовательности «прибавить 2»).

Если Лангил и в самом деле придерживался этой позиции (хотя возможно, что нет), тогда я должен с ним не согласиться. Аналогия здесь неуместна. В отличие от вопросов, которые рассматривались Витгенштейном, право это разумная деятельность: ее участники рассматривают, обсуждают и спорят о том, как им следует поступить. В отличие от описания Витгенштейном математиков и математической последовательности [2. § 240] в праве споры возникают вокруг вопроса, соблюдалось ли правило или же нет. Юридическая практика, и в части, и в целом, является предметом критики и нуждается в дальнейшем обосновании.

Исходным и основным условием понимания ограничений применения проблемы следования правилу Витгенштейна в теории права (по крайней мере, ограничений непосредственного применения) является рассмотрение того, каким образом эти соображения предназначались для отказа от языка и жизни такими, каковы они есть. Хотя при первом и поверхностном взгляде может показаться, что Витгенштейн (и некоторые его комментаторы) разделяет скептическую позицию в отношении значения, но единственная роль, которую играет скептицизм в его размышлениях о следовании правилу, - это абсурдный вывод из ошибочных посылок, который он пытался исправить: «если бы эта концепция фактов была бы правильной, тогда мы не смогли бы знать то-то и то-то, но мы это знаем, поэтому нам нужна другая концепция фактов» [27. Р. 99]. Слова имеют значение, и это - единственно правильный ответ на простые математические вопросы. Они являются отправной точкой как нашего ежедневного употребления языка, так и размышлений Витгенштейна о следовании правилу. Задача Витгенштейна была «изменить концепцию фактов, которую, как мы уверены, знаем» [27. Р. 99]; но удалось ли 
ему убедить нас, что у нас нет оснований создавать или применять правила иначе, чем мы это делаем сейчас? Если не все, то большая часть проблем в праве и в теории права возникает на другом уровне абстракции (или вообще в другой области философии), в отличие от соображений Витгенштейна о следовании правилу [28. Р. 64-68].

\section{V}

Л. Витгенштейн, обсуждая проблему следования правилу, особое внимание уделял вопросу, как объяснить согласие, которое пропитывает большую часть нашего использования языка (и математики). Но мне интересно, могут ли его замечания, хотя, определенно, и направленные на «ясные случаи», а именно на объяснение (каузальное и концептуальное) нашего согласия относительно этих случаев, помочь нам еще и объяснить нашу неспособность достичь согласия в других («сложных») случаях. Есть много причин полагать, что мы не можем напрямую применять идеи Витгенштейна к сложным случаям, потому что они были предназначены для простых случаев. Как отметил Саймон Блэкберн, именно «автоматическая и подчиняющая природа следования правилу» в ясных случаях сделала их интересными для Витгенштейна [29. Р. 170]. То, что мы думаем о простых случаях (что в них «правильно» и «неправильно), сильно отличается от сложных случаев. Блэкберн писал: «Мы можем каким-то образом обозначить себя как мыслящих истину, когда (как, например, в случае, когда мы принимаем доказательство) мы не можем образовать понятие, что это можно было бы мыслить иначе. Но отсюда вовсе не следовало бы, что то же самое обозначение имеет место, когда мы вполне осознаем возможность мыслить иначе» [29. Р. 170-171].

Джон Макдауэл предложил, как можно распространить идеи Витгенштейна относительно ясных случаев на сложные (хотя и признавал, что это может расширить идеи Витгенштейна [18. Р. 160]). Во-первых, в тех случаях, когда нет согласия в применении какого-то слова или понятия (особенно это касается оценочных понятий), все равно может произойти так, что для отдельного человека вопрос, как продолжить последовательность, может оказаться очевидным. И хотя этот человек знает, что другие с ним не согласны, он не способен понять, почему. Он мог бы отреагировать так: «Но ты же видишь..!» [2. § 231; 18. Р. 151-152]. И продолжить цитатой из «Философских исследований»: «Вот это и есть характерное выражение человека, находящегося во власти правила» [2. § 231]. Иными словами, Макдауэл предполагает, что некоторые люди во многих сложных случаях испытывают те же самые чувства, что и в легких - в случаях согласия. В своем исследовании, аналогичном работе Стэнли Фиша, он намекает, что различие между ясными и сложными случаями может отражать различие между людьми, которым одинаково «неуютно» [18. Р. 151-153], и теми, кто относится к другой стороне. Таким образом, можно заметить, что между самыми ясными из ясных случаев и самыми сложными из сложных случаев есть много промежуточных положений. Это можно установить на основании двух параметров: степени согласия среди людей и того, почему многие из них убеждены в очевидности избранного варианта (и не могут себе представить другого исхода). Например, согласие по поводу результата может быть достигнуто и при отсутствии 
у участников такой же (степени или уровня) уверенности, которая у них была бы (например) при продолжении последовательности «прибавить 2».

Во-вторых, в основании сложных случаев, по мнению Макдауэла, может лежать основополагающее согласие в том, какие аргументы считаются разумными или приемлемыми [18. Р. 160]. Эта точка зрения соответствует хорошо известной позиции юридического сообщества $[30,31]$. Адвокаты и теоретики права часто утверждают, что, несмотря на наличие незначительного согласия в отношении результатов, юридическая практика останется относительно стабильной и упорядоченной в силу некоторого грубого согласия в том, какими аргументами адвокаты и судьи могут пользоваться. Но здесь я не буду рассматривать обоснованность этого аргумента.

Если мы осторожно развиваем комментарии Витгенштейна (помня при этом, что ему нельзя приписывать все, что мы говорим, а можно лишь сказать, что это следует из его идей или что нечто сказано в его духе), то обнаружим несколько способов, как нам следовало бы начать анализ или объяснить разногласия в сложных случаях. У участников сложных случаев нет одинаковой реакции, у них нет широкой «согласованности в суждениях». Мы можем последовать за Макдауэлом и Фишем (и даже каким-то образом оправдать приписывание этой позиции Витгенштейну) и сказать, что в иной раз люди потому по-разному реагируют, что у них (или что «они разделяют») разные формы жизни ${ }^{1}$. У них разные социальные контексты, культура, практики и обучение. Среди тех, кто разделяет одинаковую форму жизни, (по определению) не будет различий в реакциях, и тогда эти случаи могут оказаться «простыми».

\section{1}

Также сложными будут случаи, когда различные реакции не могут связываться с тем, что у людей были (они разделяли) различные формы жизни. В некоторых случаях разные люди могли бы просто стремиться продолжать последовательность по-разному, даже если у них был одинаковый изначальный опыт. В этой связи У.Б. Галли предположил, что споры вокруг употребления таких терминов, как «демократия» и «произведение искусства», можно было бы объяснить тем, что разные люди по-разному интерпретируют (в терминах Витгенштейна, «разнятся») образцовые примеры, к которым эти термины должны применяться по общему согласию (аналогично изначальному остенсивному определению) [32. Р. 167].

Чтобы понять, обогатило ли обсуждение Галли наше понимание указанного разногласия, следует более внимательно рассмотреть его анализ. Что значит, когда два человека не согласны с применением понятия, но согласны с тем, что критерием понимания понятия является конкретный пример? Ка-

\footnotetext{
${ }^{1}$ «Теперь мы просим учащегося продолжить ряд за тысячу (скажем по команде „,2“) - а он записывает: 1 000, 1 004, 1 008, 1 012. Мы говорим ему: „Посмотри, что ты делаешь!“ - Он нас не понимает. Мы говорим: „Ты должен прибавлять 'два': смотри как ты начал ряд!“ - Он отвечает: „Да! А разве это неверно? Я думал, что нужно делать так“. - Или же представь себе, что он сказал, указывая на ряд: „Но ведь я действовал здесь точно так же“. - Было бы бесполезно говорить ему: „Разве ты не видишь...?“ - и повторять при этом старые пояснения и примеры. - В таком случае $м b l$ могли бы сказать: этому человеку по природе свойственно понимать наше задание и наши пояснения так, как мы понимаем задание: „До 1000 всегда прибавляй 2, до 2000 - 4, до 3000 - 6 и т.д.“” [2. § 185].
} 
жется, есть два возможных ответа, которые я назову сильным примером и безусловным примером.

В случае сильного примера человек мог бы, например, сказать: «если что-то является законом, то правила дорожного движения - это закон» [33. Р. 87-91] или «если где-либо и существовала демократическая форма правления, так это - древние Афины». Здесь образец хорошо согласуется с дорефлексивным представлением относительно понятия («закона» или «демократии»), но он не используется для определения терминов понятия. Возможно, хотя и маловероятно, что когда-нибудь можно будет заключить, что понятие фактически не подтверждается конкретным образцом [33. Р. 87-90]. Например, после более подробного исследования было установлено, что древние Афины изгнали из полиса слишком много людей, чтобы считаться демократией, или было выяснено, что новые археологические открытия подрывают наши представления о древних Афинах, к которому мы так привыкли.

В случае безусловного примера образец определяет понятия так, что сам образец никак не может пониматься иначе, как подтверждающий это понятие. И любое изменение представления относительно образца приводит к изменению представления относительно понятия. Примеры такого подхода можно обнаружить в религиозном мышлении: например, некоторые люди верят, что жить счастливо - значит по мере возможности жить так, как жил Иисус [32. Р. 168, 180-181].

Этот подход всегда чутко реагирует на нечто вроде вопроса Сократа: является ли что-то благом, потому что его любят боги, или боги его любят потому, что оно является благом? [34. С. 261]. Если благо может быть отделено от того, что предписывает Бог (или от того, как пребывает божественное), тогда, по крайней мере в принципе, понятие блага могло бы быть определено и отграничено независимо от образца и даже можно было бы обнаружить, что сам образец в некотором отношении отличается от благости. Иначе говоря, всегда есть риск, что абсолютный пример превратится в сильный пример. Но только если ответчик настаивает, что нечто является благим потому и только потому, что так повелел Бог, мы будем продолжать иметь дело с безусловным примером.

Случай безусловного примера есть не что иное, как развитая форма управления посредством остенсивного определения - «делай как я» или «следуй за мной» - со всеми недоразумениями и сомнениями, связанными с этим процессом [35. Р. 122-123]. Анализ Галли, кажется, не предлагает нового понимания источника или характера разногласий в этих случаях. Еще менее полезным для нашего анализа является случай сильного примера. Он описывает сближение (обращение к конкретному примеру как образцу), как просто обусловленное обычаем или практикой [33. Р. 65-66, 87-91], но не объясняет ни это сближение, ни расхождение в том, как рассматриваемое понятие применяется разными людьми.

\section{2}

Когда серьезные разногласия возникают в отношении определения или применения некоторого термина и когда, как кажется, нет никакой надежды, что дальнейшее обсуждение приблизит стороны к согласию, всегда есть подозрение, что стороны фактически говорят о разных вещах [32. Р. 175-176]. 
На уровне понятий (в отличие от слов, которые отсылают к отдельным материальным объектам) интересен вопрос, возможно ли вообще, чтобы люди, которые приписывают разные значения понятиям, говорили об одном и том же. Колин Макгин, например, писал:

«В случае понятий у нас нет идеи единственного означающего средства (слова), в отношении которого мы можем поставить вопрос, что обеспечивает постоянство его значения; между понятием и его содержанием не существует разрыва, который существует между словом и его значением. Понятие и есть (так сказать) его содержание» [10. Р. 146].

Рональд Дворкин, возможно, чтобы отчасти этого избежать, писал о наличии «разных концепций [одного и того же] понятия» [36. Р. 128]. Однако не совсем понятно, почему эти разные «концепции» являются разными концепциями одного и того же понятия, а не просто разными понятиями.

Галли предположил, что во многих «неизбежно бесконечных конфликтах» [32. Р. 196] по поводу религиозных, политических и художественных понятий стороны на самом деле спорят об одном и том же: различные версии каждого понятия возникают в споре из какого-то образчика (либо из единственного примера, либо из определенной традиции) [32. Р. 176]. В «Империи права» Дворкин объяснял разницу между понятием и концепцией «различием между уровнями абстракции, на которых можно изучать интерпретацию практики» [33. Р. 71]. Здесь понятия являются понятиями практики, и то, что связывает разные концепции вместе, есть то (повторяя вывод Галли), что они претендуют на описание одной и той же практики [33. Р. 43-49, 68-76]. Дворкин показал, что стороны дискуссии о творческой интерпретации социальных практик, по определению, говорят об одном и том же - об определенной практике (предварительно определенной на «доинтерпретативной» стадии [33. Р. 65-66]) в определенном сообществе. Интерпретации остаются сходными благодаря требованию прочного соответствия доинтерпретативного содержания и разделяемого взгляда на мир [33. Р. 87-89].

Следует также отметить, что Дворкин, возможно, слишком быстро отказался от возможности, что когда адвокаты и теоретики права говорят о праве, они могут говорить о разных вещах. В лучшем случае дискуссия Дворкина [33. Р. 44] показала, что у «закона» есть относительно устойчивая единственная референция, указывающая на то, что под этим названием каждодневно происходит ряд взаимосвязанных институциональных процессов. Однако то, что юристы (и социологи) не говорят друг с другом о «законе» (как о правилах и процедурах, действующих в определенном сообществе в определенное время) на разных языках, совершенно не доказывает, что они не говорят на разных языках, когда говорят о «праве» (как об особой форме социального института, общей для многих сообществ) [37. Р. 36; 38. Р. 367-370].

Мимолетное обсуждение Дворкина понятий и концепций позволяет объединять два разных аналитических подхода. Когда он писал о разных концепциях одного и того же понятия, Джон Ролз уже отчетливо проводил это различие. Ролз говорил о людях, имеющих общее понятие справедливости в том смысле, что «они осознают потребность в определенном множестве принципов относительно основных прав и обязанностей и готовы их принять; эти принципы также определяют правильное распределение выгод и тягот социальной кооперации» [39. Р. 5]. По Ролзу, согласованное понятие (благо- 
даря которому существуют различные концепции) существует потому, что «справедливость» используется просто как название определенного подраздела философии морали. В той степени, в которой разделяемое понятие имеет существенное содержание, только кое-что (если вообе что-то) предполагается (a priori или «грамматически») моральным подходом к социальному упорядочиванию ${ }^{1}$.

С другой же стороны, когда в «Империи права» Дворкин писал о разных концепциях одного и того же понятия привилегии, его подход сильно напоминал анализ «существенно оспариваемых понятий» Галли, который обсуждался ранее. Согласно Галли, расходящиеся теории иногда соотносятся как разные интерпретации одного и того же действия. Подход Ролза не подходит для интерпретации действий, а подход Галли не подходит для сугубо абстрактных понятий, и если смешать эти два подхода, может получиться неточной анализ.

\section{VI}

Пол Джонстон в книге «Витгенштейн и философия морали» объяснил, как в контексте подхода Витгенштейна к языку и морали можно понять, по крайней мере, некоторые расхождения во мнениях относительно сложных случаев. Его анализ был основан на «грамматических различиях этических и неэтических языковых игр» [40. Р. 93], на разном применении дескриптивных и оценочных терминов. Должен ли использоваться отдельный дескриптивный термин («красный», «банан», «стол» и т.д.), это зависит от применения правил, задающих значение термина, и от согласованных проверочных процедур (например, сравнение объекта с общепризнанным образцом цвета, чтобы установить, действительно ли объект красный) [40. Р. 95-96]. Языковая игра по поводу дескриптивных терминов предполагает и зависит от устойчивого согласия в применении правил и проверочных процедур [40. Р. 96].

Напротив, оценочные термины служат для других функций и образованы они иначе. Такие термины, как «хороший» и «благородный», согласно этому анализу, отражают одобрение говорящим описываемых объектов или деятельности и что объекты соответствуют его этической системе. То есть эти термины показывают, каким образом говорящий смотрит на мир и на жизнь в мире. «Здесь согласие в реакциях предполагается [только] в том смысле, что наша способность употреблять слова вроде „хороший“ включает в себя такую реакцию, которая распознается другими как одобрение и т.д.» [40. Р. 96] Нет установленных критериев применения оценочных терминов. А поскольку применение таких терминов отражает этические системы разных людей, то следует ожидать и расхождений в употреблении, а не ставить под сомнение языковую игру [40. Р. 99-101].

Прочтение Джонстоном Витгенштейна позволяет объяснить существование сложных случаев, в которых используются моральные или оценочные выражения (например, «разумные цены», «недобросовестность», «надлежащая процедура»), и выяснить, почему в отношении таких случаев не стоит ожидать согласия.

${ }^{1}$ «Между людьми не делается произвольных различий в отношении основных прав и обязанностей и когда правила определяют надлежащий баланс между конкурирующими притязаниями» [39. P. 5]. 


\section{Заключение}

И сторонники, и противники радикальной неопределенности права пытались использовать обсуждение Л. Витгенштейном следования правилу для обоснования своих позиций. На мой взгляд, обе стороны находят в Витгенштейне больше, чем есть на самом деле. Тем не менее использование обсуждения следования правилу для понимания проблемы ясных и сложных случаев весьма ограничено.

Некоторые ясные случаи являются ясными по большей части из-за (краткосрочной) определенности дескриптивных терминов. Наше согласие в применении таких терминов обусловлено неким сочетанием нашей человеческой природы, общей подготовки и общего образа жизни. И хотя Витгенштейн подробно не рассматривал ситуации отсутствия согласия, но из его работ можно вывести возможное объяснение сложных случаев: например, что у людей могут быть разные формы жизни или что ключевые термины являются скорее оценочными, чем дескриптивными.

\section{Литература}

1. Baker G.P., Hacker P.M.S. Wittgenstein: Rules, Grammar and Necessity. Oxford : Basil Blackwell, 1985.

2. Витгенштейн Л. Философские исследования // Философские работы. М. : Гнозис, 1994. Ч. I. C. $75-320$.

3. Kripke S. Wittgenstein on Rules and Private Language. Cambridge, Mass. : Harvard University Press, 1982. 636.

4. Yablon C.M. Law and Metaphysics // The Yale Law Review. 1987. Vol. 96, № 3. P. 613-

5. Yablon C.M. The Indeterminacy of the Law: Critical Legal Studies and the Problem of Legal Explanation // Cardozo Law Review. 1985. Vol. 6. P. 917-945.

6. Tushnet M. Red, White and Blue: Critical Analysis of Constitutional Law. Cambridge, Mass. : Harvard University Press, 1988.

7. McDowell J. Wittgenstein On Following a Rule// Synthese. 1984. Vol. 58. P. 325-363.

8. Blackburn S. The Individual Strikes Back // Synthese. 1984. Vol. 58. P. 281-301.

9. Baker G.P., Hacker P.M.S. Scepticism, Rules and Language. Oxford : Basil Blackwell, 1984.

10. McGinn C. Wittgenstein on Meaning. Oxford : Basil Blackwell, 1984.

11. Goldfarb E. Kripke on Wittgenstein on Rules // The Journal of Philosophy. 1985. Vol. 82, № 9. P. 471-488.

12. Malcolm N. Nothing is Hidden. Oxford : Basil Blackwell, 1986.

13. Pears D. The False Prison: A Study of the Development of Wittgenstein's Philosophy. Oxford : Clarendon Press, 1988. Vol. 2.

14. Lewis A. Wittgenstein and Rule-Scepticism // The Philosophical Quarterly. 1988. Vol. 38, № 152. P. 280-304.

15. Wright C. The Critical Notice // Mind. 1989. Vol. 98. P. 289-305.

16. Витгенштейн Л. Логико-философский трактат // Философские работы. М. : Гнозис, 1994. Ч. I. C. $1-73$.

17. Wittgenstein L. Zettel. Berkeley, Calif. : University of California Press, 1970.

18. McDowell J. Non-Cognitivism and Rule-Following // Wittgenstein: To Follow a Rule / edited by S. Holtzman \& C. Leich. London : Routledge \& Kegan Paul, 1981. P. 141-162.

19. Wittgenstein L. Remarks on the Foundations of Mathematics. Oxford : Basil Blackwell, 1956.

20. Pears D. Ludwig Wittgenstein. Cambridge, Mass. : Harvard University Press, 1986.

21. Haller R. Questions on Wittgenstein. Bristol: Routledge, 1988.

22. Wittgenstein L. Lectures and Conversations on Aesthetics, Psychology and Religious Belief. Oxford : Basil Blackwell, 1978.

23. Langille B. Revolution Without Foundation: The Grammar of Scepticism and Law // McGill Law Journal. 1988. Vol. 33, № 3. P. 451-505. 
24. Hutchinson A. That's Just the Way it Is: Langille on Law // McGill Law Journal. 1989. Vol. 34, № 1. P. 145-159.

25. Langille B. The Jurisprudence of Despair, Again // University of British Columbia Law Review. 1989. Vol. 23. P. 549-565.

26. Wolgast E. The Grammar of Justice. London : Cornell University Press, 1987.

27. Blackburn S. Spreading the Word. Oxford : The Clarendon Press, 1984.

28. Schauer F. Playing by the Rules: A Philosophical Examination of Rule-Based DecisionMaking in Law and in Life. Oxford: The Clarendon Press, 1991.

29. Blackburn S. Rule-Following and Moral Realism // Wittgenstein: To Follow a Rule / ed. by S. Holtzman, C. Leich. London : Routledge \& Kegan Paul, 1981. P. 163-187.

30. Bell J. The Acceptability of Legal Arguments // The Legal Mind / ed. by N. MacCormick,

P. Birks. Oxford : The Clarendon Press, 1986. P. 45-65.

31. Fiss O.M. Objectivity and Interpretation // Stanford Law Review. 1982. Vol. 34. P. 739764.

32. Gallie W.B. Essentially Contested Concepts // Proceedings of the Aristotelian Society. 1955. Vol. 56. P. 167-198.

33. Dworkin R. Law's Empire. Cambridge, Mass. : Harvard University Press, 1986.

34. Платон. Евтифрон.

35. Hart H.L.A. The Concept of Law. Oxford : The Clarendon Press, 1961.

36. Dworkin R. Taking Rights Seriously. Cambridge, Mass: Harvard University Press, 1978.

37. Hart H.L.A. Comment on Dworkin // Issues in Contemporary Legal Philosophy / ed. by R. Gavison. Oxford : The Clarendon Press, 1987. P. 35-42.

38. Finnis J. On Reason and Authority in Law's Empire // Law and Philosophy. 1987. Vol. 6. P. 357-380.

39. Rawls J.A Theory of Justice. Cambridge, Mass : Belknap Press, 1972.

40. Johnston P. Wittgenstein and Moral Philosophy. London : Routledge \& Kegan Paul, 1989.

Brian Bix, University of Minnesota (Minneapolis, USA).

E-mail: bix@umn.edu

Vestnik Tomskogo gosudarstvennogo universiteta. Filosofiya. Sotsiologiya. Politologiya - Tomsk

State University Journal of Philosophy, Sociology and Political Science. 2020. 58. pp. 303-319.

DOI: $10.17223 / 1998863 \mathrm{X} / 58 / 31$

THE APPLICATION (AND MIS-APPLICATION) OF WITTGENSTEIN'S RULEFOLLOWING CONSIDERATIONS TO LEGAL THEORY

Keywords: rule-following; legal theory; legal language; Wittgenstein.

Wittgenstein's writings on "rule-following" are an important, and sharply contested, part of his later thought. The reference to "rules" in those writings was both broader and more basic than the use of that term in most discussions of practical reasoning or legal theory. Wittgenstein's use of "rule" refers to all normative constraints which apply over an indefinite variety of cases, to practices where our actions might be said to be guided, to situations where characterizing actions as "correct" or "incorrect" makes sense. Wittgenstein focused in particular on normative practices that on the surface do not seem troubling or difficult to understand: for example, using a word correctly, understanding a signpost, and continuing a simple mathematical series. In such examples, the interesting question is not whether a particular response or continuation is right or wrong; Wittgenstein specifically chose examples where there would be consensus on that issue. Wittgenstein's question is what is it about the rule or about ourselves which makes our responses right or wrong (or which justifies us in reaching that evaluation)? The article explores Wittgenstein's work. more recent commentaries on that work, and efforts by some legal theorists to apply the rule-following considerations to issues of legal interpretation. Both proponents and opponents of radical legal indeterminacy have tried to use Wittgenstein's discussions on rule-following to ground their positions. Ultimately, both sides find more in Wittgenstein than is actually there. The discussions on rule-following do, however, have some limited use in understanding the problem of easy cases and hard cases. Some easy cases are easy because of the (short-term) determinacy of descriptive terms. Our consensus in applying such terms is due to some combination of our common human nature, our common training, and our common way of life. Wittgenstein did not discuss extensively cases the situation where consensus was absent, though some potential explanations for hard cases can be derived from his writing: e.g., that the people involved have different forms of life or that the key terms are evaluative rather than descriptive. 


\section{References}

1. Baker, G.P. \& Hacker, P.M.S. (1985) Wittgenstein: Rules, Grammar and Necessity. Oxford: Basil Blackwell.

2. Wittgenstein, L. (1994a) Filosofskie raboty [Philosophical Studies]. Vol. 1. Moscow: Gnozis. pp. $75-320$.

3. Kripke, S. (1982) Wittgenstein on Rules and Private Language. Cambridge, Mass.: Harvard University Press.

4. Yablon, C.M. (1987) Law and Metaphysics. The Yale Law Review. 96(3). pp. 613-636.

5. Yablon, C.M. (1985) The Indeterminacy of the Law: Critical Legal Studies and the Problem of Legal Explanation. Cardozo Law Review. 6. pp. 917-945.

6. Tushnet, M. (1988) Red, White and Blue: Critical Analysis of Constitutional Law. Cambridge, Mass.: Harvard University Press.

7. McDowell, J. (1984) Wittgenstein On Following a Rule. Synthese. 58. pp. 325-363. DOI: 10.1007/BF00485246

8. Blackburn, S. (1984) The Individual Strikes Back. Synthese. 58. pp. 281-301. DOI: 10.1007/BF00485244

9. Baker, G.P. \& Hacker, P.M.S. (1984) Scepticism, Rules and Language. Oxford: Basil Blackwell, 1984.

10. McGinn, C. (1984) Wittgenstein on Meaning. Oxford: Basil Blackwell.

11. Goldfarb, E. (1985) Kripke on Wittgenstein on Rules. The Journal of Philosophy. 82(9). pp. 471-488.

12. Malcolm, N. (1986) Nothing is Hidden. Oxford: Basil Blackwell.

13. Pears, D. (1988) The False Prison: A Study of the Development of Wittgenstein's Philosophy Vol. 2. Oxford: Clarendon Press.

14. Lewis, A. (1988) Wittgenstein and Rule-Scepticism. The Philosophical Quarterly. 38(152). pp. 280-304. DOI: $10.2307 / 2220128$

15. Wright, C. (1989) The Critical Notice. Mind. 98. pp. 289-305.

16. Wittgenstein, L. (1994b) Filosofskie raboty [Philosophical Studies]. Vol. 1. Moscow: Gnozis. pp. 1-73.

17. Wittgenstein, L. (1970) Zettel. Berkeley, Calif.: University of California Press.

18. McDowell, J. (1981) Non-Cognitivism and Rule-Following. In: Holtzman, S. \& Leich, C. (eds) Wittgenstein: To Follow a Rule. London: Routledge \& Kegan Paul. pp. 141-162.

19. Wittgenstein, L. (1956) Remarks on the Foundations of Mathematics. Oxford: Basil Blackwell.

20. Pears, D. (1986) Ludwig Wittgenstein. Cambridge, Mass.: Harvard University Press.

21. Haller, R. (1988) Questions on Wittgenstein. Bristol: Routledge.

22. Wittgenstein, L. (1978) Lectures and Conversations on Aesthetics, Psychology and Religious Belief. Oxford: Basil Blackwell.

23. Langille, B. (1988) Revolution Without Foundation: The Grammar of Scepticism and Law. McGill Law Journal. 33(3). pp. 451-505.

24. Hutchinson, A. (1989) That's Just the Way it Is: Langille on Law. McGill Law Journal. 34(1). pp. $145-159$.

25. Langille, B. (1989) The Jurisprudence of Despair, Again. University of British Columbia Law Review. 23. pp. 549-565.

26. Wolgast, E. (1987) The Grammar of Justice. London: Cornell University Press.

27. Blackburn, S. (1984) Spreading the Word. Oxford: The Clarendon Press.

28. Schauer, F. (1991) Playing by the Rules: A Philosophical Examination of Rule-Based Decision-Making in Law and in Life. Oxford: The Clarendon Press.

29. Blackburn, S. (1981) Rule-Following and Moral Realism. In: Holtzman, S. \& Leich, C. (eds) Wittgenstein: To Follow a Rule. London: Routledge \& Kegan Paul. pp. 163-187.

30. Bell, J. (1986) The Acceptability of Legal Arguments. In: MacCormick, N. \& Birks, P. (eds) The Legal Mind. Oxford: The Clarendon Press. pp. 45-65.

31. Fiss, O.M. (1982) Objectivity and Interpretation. Stanford Law Review. 34. pp. 739-764.

32. Gallie, W.B. (1955) Essentially Contested Concepts. Proceedings of the Aristotelian Society. 56. pp. 167-198. DOI: 10.1080/13569310600923782

33. Dworkin, R. (1986) Law's Empire. Cambridge, Mass.: Harvard University Press.

34. Plato. (s.n.) Evtifron [Euthyphro]. Translated from Ancient Greek. [s.l., s.n.]

35. Hart, H.L.A. (1961) The Concept of Law. Oxford: The Clarendon Press.

36. Dworkin, R. (1978) Taking Rights Seriously. Cambridge, Mass: Harvard University Press. 
37. Hart, H.L.A. (1987) Comment on Dworkin. In: Gavison, R. (ed.) Issues in Contemporary Legal Philosophy. Oxford: The Clarendon Press. pp. 35-42.

38. Finnis, J. (1987) On Reason and Authority in Law's Empire. Law and Philosophy. 6. pp. 357-380. DOI: 10.1007/BF00142932

39. Rawls, J. (1972) A Theory of Justice. Cambridge, Mass: Belknap Press.

40. Johnston, P. (1989) Wittgenstein and Moral Philosophy. London: Routledge \& Kegan Paul. 